\title{
Pearls and pitfalls in diagnosing prostate cancer using multiparametric MRI (mpMRI)
}

\author{
JJ Joshi", S Lee, P Acher, SH Liyanage \\ From International Cancer Imaging Society Meeting and 15th Annual Teaching Course (ICIS 2015) \\ London, UK. 5-7 October 2015
}

\section{Learning objectives}

Using our experience of over 500 patients who have undergone pre-biopsy mpMRI (T2, DWI +/- DCE) and subsequent transperineal saturation prostate biopsy, we aim to:

- Illustrate the commonly overlooked areas in diagnosing prostate cancer with mpMRI.

- Emphasise technical factors that can contribute to suboptimal image interpretation.

- Highlight normal anatomical structures and noncancerous abnormalities that mimic tumour.

- Demonstrate the use of mpMRI to direct further management.

\section{Content organisation}

mpMRI may be used in the pre-biopsy setting to determine type of biopsy (targeted vs. transperineal vs. transrectal), and predict biopsy outcome to the extent that biopsies may be avoided altogether. Tumour localisation within the prostate gland aids targeted biopsy and influences treatment (e.g. suitability for nerve sparing or radiation dose escalation). Tumours with unusual appearances and those in uncommon sites hinder MRI interpretation, potentially leading to false-negative or positive findings. These areas of pitfall can be divided into normal anatomical structures in the peripheral or transitional zones or non-cancerous abnormalities that mimic tumours (e.g. granulomatous prostatitis).

It is also important to acknowledge that mpMRI itself has limitations. Technical challenges in relation to DWI may lower tumour sensitivity due to anatomical distortion, inadequate suppression of benign prostate tissue and suboptimal ADC map windowing.

* Correspondence: jayjoshi20@gmail.com

Southend University NHS Hospital Trust, UK

\section{Conclusion}

It is paramount that radiologists are aware of the commonly missed locations of prostate cancer, tumour mimics and the limitations of mpMRI, particularly in the context of a multidisciplinary team setting. This would serve to improve diagnostic accuracy, target areas for biopsy more precisely and correctly influence management.

Published: 2 October 2015

doi:10.1186/1470-7330-15-S1-P37

Cite this article as: Joshi et al:: Pearls and pitfalls in diagnosing prostate cancer using multiparametric MRI (mpMRI). Cancer Imaging 2015 15(Suppl 1):P37.
Submit your next manuscript to BioMed Central and take full advantage of:

- Convenient online submission

- Thorough peer review

- No space constraints or color figure charges

- Immediate publication on acceptance

- Inclusion in PubMed, CAS, Scopus and Google Scholar

- Research which is freely available for redistribution
() Biomed Central 